\title{
OPERATING SPEED AND ACCIDENTS AT HORIZONTAL CURVES: INSIGHTS FROM TWO-LANE RURAL HIGHWAY IN MIXED TRAFFIC OPERATION
}

\author{
Tate Nalo', Sudipa Chatterjee ${ }^{2}$, Sudeshna Mitra ${ }^{3}$ \\ ${ }^{1}$ Urban Development \& Housing, Govt. of Arunachal Pradesh, India \\ ${ }^{2}$ Department of Civil Engineering, IIT Kharagpur, India \\ ${ }^{3}$ Global Road Safety Facility, The World Bank, Washington DC, USA
}

Received 8 August 2020; accepted 5 September 2020

\begin{abstract}
Drivers' behavior in a two-lane highway is more unprecedented as they tend to overtake at a higher speed due to undivided lanes. Also, often there are significant changes in driving speed along the horizontal curves because of the opposing traffic flow. Such variation in speed increases the likelihood of accidents on a two-lane road. In addition to that, the mix of different vehicle class often influences risky overtaking at the horizontal curves even in the absence of adequate sight distance. Keeping that in mind, the primary aim of this research was framed to obtain insight about the influence of road geometric features on operating speed and impact of speed dispersion on accidents along the horizontal curves in mixed traffic operation. The study indicates that beside road geometric features, operating speed along the horizontal curves is also influenced by traffic composition. Interestingly, it was observed that different vehicle class reacted differently while traversing a horizontal curve. Moreover, it was observed that the dispersion of speed had a significant impact on the accident counts at the horizontal curves. The insights from the study could be useful for designing of appropriate countermeasures to control the speed and reduce severe accident at horizontal curves.
\end{abstract}

Keywords: horizontal curves, mixed traffic, rural highways, road accidents, operating speed, speed dispersion.

\section{Introduction}

Speed is one of the primary factors contributing to the occurrence of traffic accidents and fatalities on two-lane highways (Chatterjee and Mitra, 2019; Abbas et al., 2011; Elvik, 2005). A driver behaves more unprecedentedly on a two-lane undivided highway, as they tend to overtake at higher speed against opposing traffic flow. Moreover, researchers (Misaghi and Hassan, 2005; Memon et al., 2008; Abdul-Mawjoud and Sofia, 2008) have also confirmed that, the quality of traffic service and safety of two-lane highways is largely influenced by the geometric design of the highway, especially the horizontal alignment. In this context, the concept of Geometric Design Consistency (GDC), has been the most promising strategy to investigate the traffic safety standards of the two-lane roads. A consistent geometric design is the one which confirms the driver's expectancy during his maneuver and lowers the probability

${ }^{2}$ Corresponding author: sudipa.chatterjee@iitkgp.ac.in 
of erroneous driving. Operating speed on horizontal curves is a major indicator of consistent design and has been widely used for evaluating prevailing safety level on two-lane highways. Therefore, to estimate the significant measure of the design consistency, an accurate operating speed prediction model is essential (Fitzpatrick, 2003). However, researchers have claimed that, speed prediction models are mostly country dependent or even sometimes region dependent in larger countries, primarily due to vast differences in demographics, traffic composition, driver behavior and attitude, levels of motor law enforcement, etc. (Lamm and Smith, 1994; Bird and Hashim, 2005). Specially, for mixed traffic condition, where the road space is shared by both the fastand slow-moving vehicles, and driver's maneuver is largely influenced by the roadside environment beside traffic interaction, developing operating speed models are very important. Hence, it becomes inevitable for the researchers to develop operating speed models based on the local conditions of the highway.

Although fatal accidents and injuries are significantly high on highways in general and two-lane highways in particular, little focus has been given on assessing impact of design in general and design consistency in particular on safety performance of these roads in India (Chatterjee and Mitra, 2019). While individual design elements of highways may conform to standards, the combination of such individual geometric elements may not be compatible and can perform inefficiently leading to driver error. However, the design consistency concept has hardly been tested for Indian highways. Further, poor GDC of the roadway segment particularly in the presence of horizontal curves, could lead to more speed variability
- increasing the probability of driver error and consequently the risk of accident. Hence, the primary objective of this research is to develop operating speed prediction models for horizontal curves of two-lane national highways in India. The proposed speed prediction model can be used to evaluate alternate designs and aid in considering the right design choice for improvement of the roads. Moreover, impact of variation in operating speed on road accidents can also help to design effective counter measures for safer roads under prevailing traffic condition.

\section{Motivation for the Study}

In general, operating speed assessment is the most commonly used criteria to evaluate GDC (Garber and Ehrhart, 2000; Fitzpatrick et al., 2000; Hassan et al., 2001; Lamm et al., 2002; Hashim et al., 2016). One of the earliest studies leading to the concept of GDC was conducted by Leisch and Leisch (1977), which widened the scope of the basic principle and intrinsic value of the designspeed concept. In this study, the authors projected speed profiles of passenger cars and trucks on the proposed highway considering horizontal and vertical alignment for a road in the United States. A continuous plot of the average speeds of vehicles along the roadway under free-flow condition was utilized to develop the speed profiles. The variations within these speed profile, presented a picture of the favorable and unfavorable operational characteristics, especially at the horizontal and vertical design elements that any other methods were unable to reflect. Although this procedure was used for designing of new facility, it was also useful for determining corrective measures to upgrade existing facilities. Another similar and noteworthy study was conducted by Lamm and Choueiri (1987), who predicted 
the 85 th percentile speeds on 261 curves in New York as a function of the degree of curvature, lane width, shoulder width and annual average daily traffic along two-lane rural highways. The authors also studied the $85^{\text {th }}$ percentile speed variation along the successive design elements. Krammes et al. (1995) in a study observed that the length of horizontal curve and deflection angle and radius of curve were statistically significant predictors of $85^{\text {th }}$ percentile speeds along horizontal alignments of two-lane rural highways in the United States. Few studies (Al-Masaeid et al., 1995; Abdelwahab et al., 1998; McFadden and Elefteriadou, 2000) focused on predicting the reduction in speed from a tangent to a curve and found strong relation between operating speed at middle of the curve with the operating speed and geometry of the successive alignments. For instance, Memon et al. (2008) in a study conducted in Pakistan with continuous speed profile data observed that the operating speed on horizontal curves was strongly related to the maximum $85^{\text {th }}$ percentile speed at the approach of the tangent and the inverse of the radius of the curve. The developed model for predicting tangent speed was also found to be highly correlated to adjacent curve geometry and the length of the tangent. However, in contrary, Misaghi and Hasan (2005) found a very weak relation between the operating speed at a horizontal curve with the successive alignment parameters. The authors argued that the reason for such contradicting findings could have been the presence of nearby intersections and driveways. Castro et al. (2011) developed models to predict operating speed and forecast the speed change experienced by drivers from tangent to curve. The model developed for operating speed prediction at the midpoint of curves was compared with similar predictive models calibrated from other countries. This comparative study highlighted the need for locally calibrated speed-prediction models. While the majority of studies focused on high-speed, twolane rural roads, Banihashemi et al. (2011) developed an operating speed prediction models for low-speed, rural two-lane highways with posted speed limit of $40-60$ $\mathrm{km} / \mathrm{h}$. The study stated that posted speed limit and length of tangent were positively association with operating speeds, while the radius of the preceding curve, roadside hazard rating, and curve radius were negatively association with operating speeds.

Limited studies are conducted in India on operating speed models at curved segments. One of the earliest studies was by Jacob and Anjaneyulu (2013a), who aimed to develop operating speed models for different vehicular classes at salient locations of multiple horizontal curves and to build criteria for evaluating the GDC for Indian Highways. The authors found that length of preceding tangent influenced operating speed at tangent and radius and length of curve significantly affected the operating speed at middle of first curve whereas operating speed at middle of second curve was dependent on the radius of first and second curve. In a similar study, Shallama and Ahmed (2016) developed speed prediction equations using data collected at 10 horizontal curves of highway from Shillong, India. The study indicated that sight distance, radius and deviation angle had significant effect on the operating speed of a vehicle traversing a curve. It was observed that while the radius of curvature had the maximum impact on the operating speed at the circular portion of the horizontal curve, the sight distance and the deviation angle had maximum impact on the operating speed at the entry of the curve. In a very recent study

\section{ijtte 484}


by Maji et al. (2018), the authors developed the $85^{\text {th }}$ and $98^{\text {th }}$ percentile speed prediction models of car, light, and heavy commercial vehicles for four-lane divided horizontal curves in rural highways using a stepwise multiple linear regression method. The $85^{\text {th }}$ percentile speed of commercial vehicles at mid-curve was found to be dependent on its speed at preceding section. However, for car, it was dependent on curve length and deflection angle. The study highlighted that designing curve length could be an important factor in the highway geometry.

From the existing literature, it was evident that the operating speed of a horizontal curve largely depends on its geometry such as the length of the curve, radius of the curve, deflection angle, sight distance, lane width, shoulder width. However, very few of the researches explored the effect of rate of superelevation on the operating speed at a horizontal curve. Moreover, literatures based on development of operating speed models for curves mostly dealt with the combination of vertical and horizontal curves on twolane highways and the prevailing scenarios for single horizontal curves at plain terrain is yet not explored in India. Additionally, studies related to the mixed traffic conditions prevailing in India are also less in numbers.

Moreover, even though there are several studies on determining accident causal factors for two-lane highways in India (Agrawal et al., 2019; Chatterjee and Mitra, 2019; Chatterjee et al., 2019; Naqvi and Tiwari, 2015; Jacob and Anjaneyulu, 2013b; Dinu and Veeraragavan, 2011) none of them specifically highlighted the effect and influence of speed on the accidents occurring on the horizontal curves separately. Hence, the study objectives are framed as follows:

- To develop operating speed models for single horizontal curve;

- To understand the relationship between the speed variation and the safety performance of a single horizontal curve.

\section{Study Methodology and Data Description}

Based on the literature survey conducted, a systematic approach was framed to critically analyze the factors affecting the operating speed on horizontal curves of NH 117 of West Bengal state, India (Fig. 1).

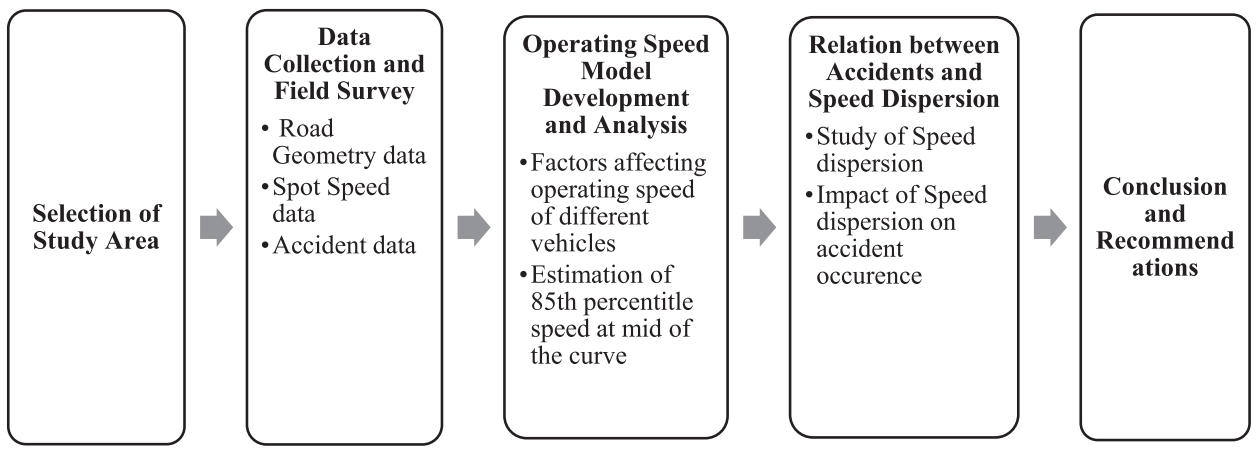

Fig. 1.

Proposed Study Methodology 


\subsection{Study Area}

A stretch of National Highway (NH) 117 was selected for the investigation. $\mathrm{NH} 117$ runs entirely on plain terrain in the state of West Bengal, India. The length of this highway is $133 \mathrm{~km}$ and passes through the districts of Howrah, Kolkata and South 24 Parganas. However, the only the part of the highway passing through South 24 parganas is two-lane undivided. A total of 52 horizontal curves were identified along the two-lane highway. However, several curves with presence of rumble strips, humps, police barricades or located at congested built-up areas and intersections were avoided. Finally, only 33 curves were considered which had unaffected free flow speed and no or less roadside frictions.

\subsection{Traffic Composition Details}

The vehicle category was classified under six groups - two wheelers (2Ws), three wheelers (3Ws), buses, cars, light commercial vehicles (LCVs) and heavy commercial vehicles (HCVs). In most of the curves the share of two wheelers was significantly high. On the contrary very few proportions of buses and heavy vehicles were observed (Table 1). Thus, the traffic composition plays an important role for determining operating speed at curve locations.

Table 1

Traffic Composition on the Study Stretch (\%)

\begin{tabular}{|l|c|c|c|c|c|c|}
\hline & 2Ws & 3Ws & Cars & LCVs & Buses & HCVs \\
\hline Minimum & 20.00 & 4.50 & 10.29 & 0.98 & 4.00 & 0.50 \\
\hline Maximum & 57.50 & 24.04 & 26.33 & 41.25 & 17.50 & 13.94 \\
\hline Average & 39.57 & 13.70 & 16.36 & 15.88 & 8.04 & 6.44 \\
\hline Standard deviation & 14.51 & 5.47 & 3.50 & 13.92 & 3.04 & 3.95 \\
\hline
\end{tabular}

\subsection{Spot Speed Data}

A spot speed study was conducted (by using Laser gun) to obtain the free flow speed of the vehicles traversing the horizontal curves. To satisfy the free flow condition, vehicles with a lead headway of 8 seconds or more and lag headway of 5 seconds or more were only considered (Sekhar et al., 2016). The speed data of a vehicle was captured at three different points of the curve i.e. entry point, mid-point and exit point of the horizontal curve. The operators of the laser guns placed themselves in such a way that their presence did not affect the speed of the vehicle. The speed was measured simultaneously in the three points of the curve to obtain the speed change patterns for vehicles along the curves (Fig. 2). A sample of 200-400 vehicles of each type were targeted on the curve locations specially during the morning and evening off-peak hours for a period of 2 days. The evening off peak hour was considered to incorporate the variation of speed due to absence of natural light. The final spot speed was obtained after applying appropriate correction for angle and distance off the roadway (Table 2 ). 


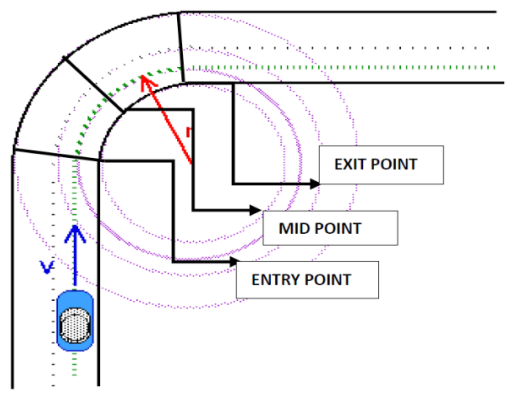

Fig. 2.

Spot Speed Measurement on a Typical Horizontal Curve

Table 2

Speed Characteristics on the Horizontal Curves

\begin{tabular}{|l|c|c|c|c|}
\hline Vehicle Category & Speed & Entry $(\mathbf{k m} / \mathbf{h})$ & Mid $(\mathbf{k m} / \mathbf{h})$ & Exit $(\mathbf{k m} / \mathbf{h})$ \\
\hline \multirow{3}{*}{$2 \mathrm{Ws}$} & Average & 61.94 & 66.83 & 69.19 \\
\cline { 2 - 5 } & Std.dev & 5.79 & 5.48 & 4.95 \\
\hline \multirow{3}{*}{ Cars } & Average & 30.25 & 25.86 & 32.33 \\
\cline { 2 - 5 } & Std.dev & 5.82 & 4.27 & 4.56 \\
\hline \multirow{3}{*}{ LCVs } & Average & 67.08 & 72.70 & 76.47 \\
\cline { 2 - 5 } & Std.dev & 7.89 & 9.04 & 6.72 \\
\hline \multirow{3}{*}{ Buses } & Average & 52.44 & 47.71 & 50.22 \\
\hline \multirow{2}{*}{ HCVs } & Std.dev & 5.19 & 4.97 & 3.05 \\
\cline { 2 - 5 } & Average & 54.78 & 50.09 & 3.86 \\
\cline { 2 - 5 } & Std.dev & 3.12 & 4.34 & 46.54 \\
\cline { 2 - 5 } & Average & 48.37 & 43.19 & 5.48 \\
\hline
\end{tabular}

Note: Std.dev = Standard deviation

From the speed study, it was observed that for vehicles with good accelerating power such as cars and $2 \mathrm{Ws}$ there is a gradual increase in the average speed along the curve. Moreover, the increasing speed profile also implied that tendency for cars and $2 \mathrm{Ws}$ to overtake at a curve is higher. However, in case of other vehicle categories whose acceleration is not comparable to cars and $2 \mathrm{Ws}$, there is a decrease in the average speed along the curve. Moreover, for such vehicles the speed attained at the midpoint of the curve is lower than that at the entry and exit of the curve. This indicates that different vehicle category behaves in a different manner while traversing a horizontal alignment. This also implied that as vehicle classes react differently, variation of speed is more near the middle of the curve.

\subsection{Road Geometry Data}

While selecting the 33 simple horizontal curves locations it was made sure that there are no intersections or access roads within $200 \mathrm{~m}$ of the curves. Consecutive curves or $\mathrm{S}$ 
curves were also not considered since studies have shown that in general, drivers behave differently in multiple consecutive horizontal curves (Jacob et al., 2013). Interestingly, none of the curves have transition curves to connect to a straight segment. The road geometric features considered for this study are summarized in Table 3.

\section{Table 3}

Road Geometry Details

\begin{tabular}{|l|l|l|l|}
\hline Road Geometry Variable & Maximum & Minimum & Standard Deviation \\
\hline Lane width, w & $7.2 \mathrm{~m}$ & $6.9 \mathrm{~m}$ & 0.09 \\
\hline Shoulder width, sw & $1.2 \mathrm{~m}$ & $0.9 \mathrm{~m}$ & 0.08 \\
\hline Curve Radius, R & $240 \mathrm{~m}$ & $550 \mathrm{~m}$ & 84.89 \\
\hline Curve length, L & $55 \mathrm{~m}$ & $250 \mathrm{~m}$ & 50.24 \\
\hline Superelevation, e & $7 \%$ & $1 \%$ & $1.8 \%$ \\
\hline Sight distance & 420 & 90 & 103.01 \\
\hline
\end{tabular}

\subsection{Accident Data}

The accident data was obtained from West Bengal police department for the 3 consecutive years of 2013-15. The data mostly included information related to time of accident, severity of accident, type of collision, road users involved in the accident, place of accident. Several information related to the weather, vehicle or road user's condition were not reported. In few cases the time and collision type of accidents were also uncertain. From the study of the accident data it was found that a high share of the accidents on these curves was run off roads and head on collisions. The insights obtained from the data indicated over speeding could be a risk factor at these selected stretches. The share of accident types experienced on the horizontal curves is represented in Fig. 3.

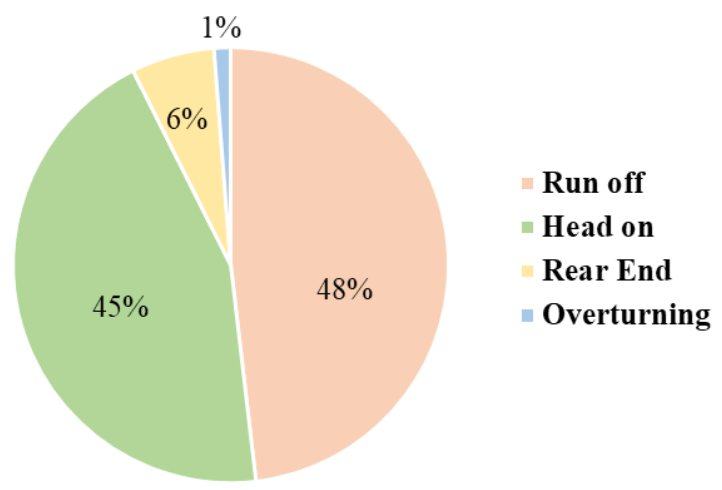

Fig. 3.

Share of Accident Types on the Study Sections 


\section{Developing Operating Speed Model}

In order to inspect the factors affecting the operating speed on the curves, multiple linear regression analysis has been carried out. In the present study, operating speed models were developed for the mid-point of the horizontal curve considering the road geometric variables and operating speed at the entry of the curve. Out of 33 horizontal curves, $80 \%$ of the data set was used for model development and the rest $20 \%$ was utilized for validation.

Before developing the operating speed model, a check was made whether the speed of the vehicles on both the directions were significantly different. In this context, a z-test for the mean speed at the mid of the curve was considered. The test was conducted for all vehicle types and a $\mathrm{p}$ value greater than
0.05 was obtained for all the vehicle classes, which indicated that there was no significant difference in the mean speeds of the sample. Therefore, the operating speed models were developed without being specific towards the direction of travel.

A correlation matrix of the independent variables selected for the analysis was studied and no strong relation was found between them $(\mathrm{R}<0.5)$. The developed operating speed model $\left(\mathrm{R}^{2}{ }_{\text {adj }}=0.76\right)$ depicted that with an increase in lane and shoulder width, the operating speed increases. Similarly, with larger curve radius and adequate sight distance, the operating speed increases. However, with the increase in curve length and superelevation the operating speed decreases. Further, it was found that the operating speed increases with increase in share of car and 2Ws (Table 4).

Table 4

Operating Speed Models on the Mid of the Horizontal Curve $\left(V_{\text {mid, } 85}\right)$

\begin{tabular}{|c|c|c|c|c|c|c|c|c|c|c|c|c|c|c|}
\hline & $\mathbf{C}$ & $\mathbf{w}$ & $\mathbf{s w}$ & $\mathbf{R}$ & $\mathbf{L}$ & $\mathbf{e}$ & $\mathbf{s d}$ & $\mathbf{V}_{\text {en,85 }}$ & $\mathbf{2 W}$ & $\mathbf{3 W}$ & $\mathbf{C a r}$ & $\mathbf{L C V}$ & $\mathbf{B u s}$ & $\mathbf{H C V}$ \\
\hline$\alpha_{i}$ & 9.65 & 0.07 & 0.33 & 0.04 & -0.02 & -7.96 & 0.21 & 0.07 & 0.14 & -0.15 & 0.28 & -0.23 & -0.11 & -0.37 \\
\hline $\mathrm{t}$ - stats & 2.12 & 1.98 & 2.4 & 2.35 & -2.10 & -3.15 & 2.98 & 4.45 & 2.72 & -2.26 & 3.51 & -3.22 & -2.63 & -4.20 \\
\hline p value & 0.02 & 0.03 & 0.01 & 0.01 & 0.02 & 0.00 & 0.00 & 0.00 & 0.00 & 0.01 & 0.00 & 0.00 & 0.01 & 0.00 \\
\hline
\end{tabular}

Note: $V_{\text {mid, } 85}=$ Operating speed at the mid of the curve $(\mathrm{km} / \mathrm{h}) ; a_{i}=$ variable coefficient; $C=$ constant; $w=$ lane width $(m), s w=$ shoulder width $(m), R=$ radius $(m) ; L=$ Length of curve $(m) ; e=$ rate of superelevation (\%); Ven,85 = Operating speed at the entry of the curve $(\mathrm{km} / \mathrm{h}) ; 2 \mathrm{~W} / 3 \mathrm{~W} / \mathrm{Car} / \mathrm{LCV} /$ Bus/HCV = percentage composition in traffic (\%).

\section{Speed Dispersion and Accident Occurrences}

As discussed in earlier sections, significant number of accidents had taken place in the curve sections. Therefore, the impact of operating speed dispersion was on accident occurrences was studied (Table 5). Speed dispersion was measured as the deviation of 15 th percentile and 85 th percentile of the traffic speed i.e. the operating speed (Wang et al., 2016). A multiple linear regression was developed in the very first step to predict speed dispersion considering the operating speed, the traffic flow rate and the composition of different vehicle categories. 


\section{Table 5}

Speed Dispersion Model

\begin{tabular}{|c|c|c|c|c|c|c|c|c|c|}
\hline & $\mathbf{C}$ & $\mathbf{V}_{\text {mid,85 }}$ & $\mathbf{f}$ & $\mathbf{2 W}$ & $\mathbf{3 W}$ & $\mathbf{C a r}$ & $\mathbf{L C V}$ & $\mathbf{B u s}$ & HCV \\
\hline$\alpha_{\mathrm{i}}$ & 7.23 & -0.38 & -0.03 & 0.47 & -0.25 & 0.82 & -0.31 & -0.12 & -0.69 \\
\hline $\mathrm{t}$ - stats & 9.12 & 6.58 & 8.74 & 4.18 & -2.93 & 7.66 & -4.49 & -3.78 & -5.26 \\
\hline p value & 0.00 & 0.00 & 0.00 & 0.00 & 0.00 & 0.00 & 0.00 & 0.00 & 0.00 \\
\hline
\end{tabular}

Note: $V_{\text {mid, } 85}=$ Operating speed at the mid of the curve $(\mathrm{km} / \mathrm{h}) ; \alpha_{i}=$ variable co-efficient; $C=$ constant; $f=$ flow rate $(v e h / h) ; 2 \mathrm{~W} / 3 \mathrm{~W} / \mathrm{Car} / \mathrm{LCV} / \mathrm{Bus} / \mathrm{HCV}=$ percentage composition in traffic (\%).

Negative Binomial (NB) model was used to predict accident count (Washington et al., 2011), due to the presence of over-dispersion of the accident data (Table 6). The negative binomial regression model associates the expected number of accident frequency at the $i^{\text {th }}$ element with probability density as shown in Eq. 1:

$P\left[Y_{i}=y_{i}\right]=\frac{e^{-\lambda_{i}} \lambda_{i}^{y_{i}}}{y_{i} !}$

Where, $Y_{i}=$ Number of accidents at road section $i$ for a chosen period of time, $\lambda_{i}=$ Intersection i's expected frequency and $\mathrm{y}_{\mathrm{i}}=$ Realized value of accident frequency at ith element, and $\mathrm{i}=1,2 \ldots \mathrm{n}$

The Negative Binomial regression model is derived by rewriting the Equation 1 as shown in Eq. 2:

$\lambda_{\mathrm{i}}=\mathrm{e}^{\left(\beta \mathrm{X}_{\mathrm{i}}+\varepsilon_{\mathrm{i}}\right)}$

$\log \left(\lambda_{\mathrm{i}}\right)=\beta_{0}+\beta_{1} \mathrm{X}_{\mathrm{i} 1}+\beta_{2} \mathrm{X}_{\mathrm{i} 2}+\beta_{3} \mathrm{X}_{\mathrm{i} 3}+$

$+\beta_{3} X_{i 3}+\ldots \ldots \ldots \ldots \ldots \ldots . . .+\beta_{k} X_{i k}+\varepsilon_{i}$
Where, $\beta=$ Vector of estimated parameters. In this context, the expected number of events per period is given by Eq. 3:

$\mathrm{E}\left[y_{i}\right]=\lambda_{i}=e^{\beta X_{i}}$

Where, $X_{i}=$ element i's explanatory variables, and $\varepsilon_{i}=$ error term (omitted explanatory variables or intrinsic randomness).

The overall goodness of the fit was denoted by $\rho^{2}$ as shown in Eq. 4. A $\rho^{2}$ value closer to 1 indicates that the model explains most of the variability of the dependent variable.

$\rho^{2}=1-[\mathrm{L}(\beta)-\mathrm{L}(0)]$

Where, $\rho^{2}=$ log-likelihood ratio index, $\mathrm{L}(\beta)$ $=$ model dispersion parameter and $\mathrm{L}(0)=$ maximum dispersion parameter of the model.

\section{Table 6}

Speed Dispersion and Accidents

\begin{tabular}{|l|c|c|}
\hline \multirow{2}{*}{ Variables } & NB Model - Constant Only & NB Model - Speed Dispersion \\
\cline { 2 - 3 } & \multicolumn{2}{|c|}{ Model Coefficients } \\
\hline Constant & $1.24(\mathrm{t}=6.58)^{* *}$ & $-0.47(\mathrm{t}=-1.98)^{* *}$ \\
\hline Speed Dispersion & -- & $0.13(\mathrm{t}=5.28, \mathrm{p}=0.00)^{* *}$ \\
\hline & \multicolumn{2}{|c|}{ Dispersion parameter } \\
\hline Alpha $(\alpha)$ & \multicolumn{2}{|c|}{$0.31(\mathrm{t}=2.09)^{* *}$} \\
\hline & \multicolumn{2}{|c|}{ Goodness-of-fit } \\
\hline Log-Likelihood Function & $-\mathrm{t}=1.73)^{*}$ & -39.23 \\
\hline Restricted Log-Likelihood Function & -56.77 & -56.06 \\
\hline$\rho^{2}$ & 0.10 & 0.30 \\
\hline
\end{tabular}

Note: *Significant at $90 \%$ CI; ${ }^{* *}$ Significant at $95 \%$ CI 
The result obtained from the statistical model confirmed that speed dispersion was significantly and positively associated with accidents on the horizontal curves. Thus, curves with higher vehicular interaction and speed dispersion had higher risk of accidents.

\section{Conclusion and Recommendations}

The broad objective of the research work was to investigate the factors influencing the operating speed characteristics on horizontal curves of two-lane highway. The statistical analysis carried out delivered insight on how the operating speed was being affected particularly by the geometric features and traffic composition of the road. Similar to the previous studies conducted in India, it was observed that with the increase in the radius of the curve the operating speed of at the mid-point of the curve increases. However, from the study it was found that with increase in the length of curve and rate of superelevation the operating speed decreases. Additionally, availability of adequate sight distance, increase in lane width and shoulder width also influences the operating speed of vehicles.

Interestingly, the study showed that with higher speed dispersion, the risk of accidents increases, i.e., variation in speed increased the probability of accident occurrence on two-lane roads. So, for safe negotiation on such horizontal curves, it is important to maintain a safe speed limit. The observations made in the study can guide engineers and policy makers in proactive safety planning and scientific design of countermeasures on accident-prone horizontal curves. For instances, it was observed that different vehicles behave in a dissimilar manner while traversing the horizontal curve. Thus, it is important to study the vehicle composition and design countermeasures as per the need of the vehicle types. Like for example, for traffic with higher share of cars and 2Ws, the operating speed of the traffic stream may be increasing gradually while traversing the curve. Therefore, it will be better to provide rumble strips at a regular interval throughout the horizontal alignment, in that way the speed will be controlled effectively and vehicles will not get a chance to accelerate. Alternatively, speed tables at the mid of the curve could help to reduce the negotiating speed of such fast vehicles at the mid of the curve and thus increase safety. However, providing a hump at the entry of the curve may not be that effective in such cases. Similarly, if the composition of cars and 2Ws are lesser as compared to LCVs and $3 \mathrm{Ws}$, then it will be more appropriate to guide traffic than to control speed. Thus, providing edge rumble strip and flexible poles can also work effectively by reducing overtaking in such locations. Alternatively, if the traffic composition and operating speed of the curve could be defined before planning or if there exists a scope for realignment of the curves, then appropriate combination of curve radius, length and rate of super elevation can help achieve better consistency in geometric design.

Similar to the other studies conducted, the present study is not without its limitations. However, the study provided some interesting insights unique for mixed traffic operation that can aid the design practices and promote safer road design.

\section{References}

Abbas, S.K.S.; Adnan, M.A.; Endut, I.R. 2011. Exploration of 85th percentile operating speed model on horizontal curve: a case study for two-lane rural highways, Procedia-Social and behavioral sciences 16: 352-363. 
Abdelwahab, W.M.; Aboul-Ela, M.T.; Morrall,J.F. 1998. Geometric design consistency based on speed change on horizontal curves, Road and Transport Research 7(1): 13-23.

Abdul-Mawjoud, A.A.; Sofia, G.G. 2008. Development of models for predicting speed on horizontal curves for two-lane rural highways, Arabian Journal for Science and Engineering 33(2B): 365-377.

Agrawal, V.; Chatterjee, S.; Mitra, S. 2019. Crash Severity Analysis Through Nonparametric Machine Learning Methods, Journal of the Eastern Asia Society for Transportation Studies 13: 2614-2629.

Al-Masaeid, H.R.; Hamed, M.; Aboul-Ela, M.; Ghannam, A.G. 1995. Consistency of horizontal alignment for different vehicle classes, Transportation Research Record 1500: 178-183.

Banihashemi, M.; Dimaiuta, M.; Wang, H. 2011. Operating Speed Model for Low-speed Rural Two-Lane Highways: Design Consistency Module for Interactive Highway Safety Design Model, Transportation Research Record2223(1): 63-71.

Bird, R.N.; Hashim, I.H. 2005. Operating speed and geometry relationships for rural single carriageways in the UK. In $3^{\text {rd }}$ International Symposium on Highway Geometric Design, Chicago Illinois, United States. 22p.

Castro, M.; Sánchez, J.F.; Sánchez, J.A.; Iglesias, L. 2011. Operating speed and speed differential for highway design consistency, Journal of Transportation Engineering 137(11): 837-840.

Chatterjee, S.; Bandyopadhyaya, P. S.; Mitra, S. 2019. Identifying Critical Safety Issues on Two Lane National Highways in India - A Case Study from NH 117 and NH 60. In $15^{\text {th }}$ World Conference on Transport Research - WCTR, Mumbai, India.

Chatterjee, S.; Mitra, S. 2019. Safety assessment of twolane highway using a combined proactive and reactive approach: case study from Indian national highways, Transportation Research Record 2673(7): 709-721.
Dinu, R.R.; Veeraragavan, A. 2011. Random parameter models for accident prediction on two-lane undivided highways in India, Journal of Safety Research 42(1): 39-42.

Elvik, R. 2005. Speed and road safety: synthesis of evidence from evaluation studies, Transportation Research Record 1908(1): 59-69.

Fitzpatrick, K. 2003. Design speed, operating speed, and posted speed practices. National Cooperative Highway Research Program. Transportation Research Board. $92 \mathrm{p}$.

Fitzpatrick, K.; Wooldridge, M.D.; Tsimhoni, O.; Collins, J.M.; Green, P.; Bauer, K.M.; Parma, K.D.; Koppa, R.; Harwood, D.W.; Anderson, I.; Krammes, R.A. 2000. Alternative design consistency rating methods for two-lane rural highways final report. FHWA-RD-99-172. Texas Transportation Institute, USA.

Garber, N.J.; Ehrhart, A.A. 2000. The effect of speed, flow, and geometric characteristics on crash rates for different types of Virginia highways (No. FHWA/VTRC 00-R15). Virginia Transportation Research Council.

Hashim, I.H.; Abdel-Wahed, T.A.; Moustafa, Y. 2016. Toward an operating speed profile model for rural twolane roads in Egypt, Journal of traffic and transportation engineering (English edition) 3(1): 82-88.

Hassan, Y.; Sayed, T.; Tabernero, V. 2001. Establishing practical approach for design consistency evaluation, Journal of transportation Engineering 127(4): 295-302.

Jacob, A.; Anjaneyulu, M.V.L.R. 2013a. Operating speed of different classes of vehicles at horizontal curves on two-lane rural highways, Journal of Transportation Engineering 139(3): 287-294.

Jacob, A.; Anjaneyulu, M.V.L.R. 2013b. Development of crash prediction models for two-lane rural highways using regression analysis, Highway Research Journal 6(1): 59-70.

\section{jitte 492}


Jacob, A.; Dhanya, R.; Anjaneyulu, M.V.L.R. 2013. Geometric design consistency of multiple horizontal curves on two-lane rural highways, Procedia-social and Behavioral Sciences 104: 1068-1077.

Krammes, R.A.; Brackett, R.Q.; Shafer, M.A.; Ottesen, J.L.; Anderson, I.B.; Fink, K.L.; Collins, K.M.; Pendleton, O.J.; Messer, C.J. 1995. Horizontal alignment design consistency for rural two-lane highways (No. FHWA-RD-94-034). Federal Highway Administration, United States.

Lamm, R.; Choueiri, E.M. 1987. Recommendations for evaluating horizontal design consistency based on investigations in the state of New York, Transportation Research Record 1122: 68-78.

Lamm, R.; Smith, B.L. 1994. Curvilinear alinement: an important issue for more consistent and safer road characteristic, Transportation Research Record 1445: 12-21.

Lamm, R.; Psarianos, B.; Cafiso, S. 2002. Safety evaluation process for two-lane rural roads: A 10-year review, Transportation Research Record 1796(1): 51-59.

Leisch, J.E.; Leisch, J.P. 1977. New concepts in designspeed application, Transportation Research Record 631: 4-14.

Maji, A.; Sil, G.; Tyagi, A. 2018. $85^{\text {th }}$ and $98^{\text {th }}$ percentile speed prediction models of car, light, and heavy commercial vehicles for four-lane divided rural highways, Journal of Transportation Engineering, Part A: Systems 144(5) 04018009:1-8. doi: https://doi. org/10.1061/JTEPBS.0000136.

McFadden, J.; Elefteriadou, L. 2000. Evaluating horizontal alignment design consistency of two-lane rural highways: Development of new procedure, Transportation Research Record 1737(1): 9-17.

Memon, R.A.; Khaskheli, G.B.; Qureshi, A.S. 2008. Operating speed models for two-lane rural roads in Pakistan, Canadian Journal of Civil Engineering 35(5): 443-453.
Misaghi, P.; Hassan, Y. 2005. Modeling operating speed and speed differential on two-lane rural roads, Journal of Transportation Engineering 131(6): 408-418.

Naqvi, H.M.; Tiwari, G. 2015. Accident Analysis of a Two-Lane National Highway in India. In Symposium on International Automotive Technology 2015. 6 p. Available from Internet: <https://doi.org/10.4271/2015-26$0162>$.

Sekhar, C.R.; Nataraju, J.; Velmurugan, S.; Kumar, P.; Sitaramanjaneyulu, K. 2016. Free flow speed analysis of two lane inter urban highways, Transportation Research Procedia 17: 664-673.

Shallama, R.D.K.; Ahmed, A.M. 2016. Operating Speed Models on Horizontal Curves for Two-lane Highways, Transportation Research Procedia 17: 445-451.

Wang, F.; Ruan, S.; Dai, M. 2016. Characteristics of speed dispersion in urban expressway, International Journal of Civil, Environmental, Structural, Construction and Architectural Engineering 10(3): 288-292.

Washington, S.; Karlaftis, M.G.; Mannering, F.; Anastasopoulos, P. 2020. Statistical and econometric methods for transportation data analysis. CRC press. 413 p. 